\title{
FORMACIÓN CIENTÍFICA STEM, EXPERIENCIAS DE APRENDIZAJE A PARTIR DE CLUBES DE CIENCIAS
}

\author{
SCIENTIFIC TRAINING STEM, LEARNING EXPERIENCES FROM SCIENCE \\ CLUBS
}

\section{TREINAMENTO CIENTÍFICO STEM, EXPERIÊNCIAS DE APRENDIZAGEM DE CLUBES DE CIÊNCIA}

\author{
Carmen del Pilar Suárez Rodríguez ${ }^{1}$ \\ Roxana de León-Lomelí ${ }^{2}$ \\ Rubi Gamboa-León ${ }^{3}$ \\ Cynthia Zamora-Pedraza ${ }^{4}$
}

\begin{abstract}
RESUMEN
La enseñanza del pensamiento lógico como actividad orientada a la educación científica, contribuye a la formación de ciudadanos críticos, tanto en escenarios formales como no formales. Dentro de los clubes de ciencia se guía a los niños a un proceso formal de investigación, que incluye la exposición y divulgación de resultados. El presente documento describe la metodología de trabajo implementada con niños de 4 hasta 12 años de edad, los actores, sus roles y los productos generados a lo largo de cinco años de su puesta en marcha en comunidades urbanas y rurales de México. Se integran las experiencias generadas en dos clubes de ciencias. Con este respaldo se elaboró una guía de trabajo sistematizada para una mejora de la práctica. Como parte de la evaluación, se han realizado entrevistas a los niños participantes, que han permitido conocer sus percepciones hacia el trabajo que realizan dentro de los mismos, con lo cual se realizó un análisis descriptivo de las experiencias. En el ciclo de trabajo reportado, se ha logrado formar a más de 50 niños, quienes han tenido un desempeño sobresaliente en concursos de ciencia a nivel nacional e internacional, que les ha permitido mejorar sus habilidades investigativas, de argumentación y de solución de problemas. El trabajo realizado ha permitido contribuir positivamente en la formación de los niños, así como la forma en la que realizan propuestas
\end{abstract}

1 Doctora por el Instituto Politécnico Nacional (IPN), Ciudad de México, México. Profesora Investigadora, Universidad Autónoma de San Luis Potosí (UASLP), Tamazunchale, San Luis Potosí, México. Dirección para correspondencia: km 5 Carretera Tamazunchale-San Martin, Tamazunchale, San Luis Potosí, México. C. P. 79960. E-mail: pilar.suarez@uaslp.mx.

2 Doctora por la Universidad Autónoma de San Luis Potosí, México. Profesora investigadora del TecNM Instituto Tecnológico de San Luis Potosí. Dirección para correspondencia: Quinta arbolada, calle 2 número 112, quintas de la hacienda, Soledad de Graciano Sánchez, San Luis Potosí, México. Email: roxana.deleon@gmail.com.

3 Doctora por la Universidad de Guadalajara, Guadalajara Jalisco, México Profesora Investigadora, Universidad Autónoma de San Luis Potosí (UASLP), Tamazunchale, San Luis Potosí, México. Dirección para correspondencia: km 5 Carretera Tamazunchale-San Martin, Tamazunchale, San Luis Potosí, México. C. P. 79960. E-mail: rubi.gamboa@uaslp.mx.

4 Doctora por la Universidad Autónoma de San Luis Potosí (UASLP), San Luis Potosí, México. Profesora Investigadora, Escuela Normal de Estudios Superiores del Magisterio Potosino (ENESMAPO). Dirección para correspondencia: Calle San Carlos 345, San Ángel Segunda sección San Luis Potosí. S. L. P. México. C.P. 78120. E-mail: czamorapedraza@yahoo.com.mx. 
de solución a problemas, evalúan la calidad de las fuentes y realizan las argumentaciones durante el desarrollo y presentación de los trabajos.

Palabras clave: Clubes de ciencia. Vocaciones científicas. Divulgación. Formación científica. Niños.

\begin{abstract}
The teaching of logical thinking as an activity oriented to scientific education contributes to the training of critical citizens, both in formal and non-formal scenarios. Within science clubs, children are guided to a formal research process, including exposure and disclosure of results. This document describes the working methodology implemented with children aged 4 to 12 years, actors, their roles and the products generated over five years of their implementation in urban and rural communities in Mexico. The experiences generated in two science clubs are integrated. With this support, a systematized working guide was developed for improved practice. As part of the evaluation, interviews have been conducted with the participating children, who have made it possible to know their perceptions of the work they do within them, with which a descriptive analysis of the experiences was carried out. In the reported work cycle, more than 50 children have been trained, who have performed outstandingly in national and international science competitions, which has enabled them to improve their investigative, argumentation and problem-solving skills. The work carried out has made it possible to contribute positively to the training of children, as well as the way in which they make problem-solving proposals, evaluate the quality of sources and make arguments during the development and presentation of the work.
\end{abstract}

Keywords: Science clubs. Scientific vocations. Outreach. Scientific training. Children.

\title{
RESUMO
}

O ensino do pensamento lógico como atividade orientada para a educação científica contribui para a formação de cidadãos críticos, tanto em contextos formais como não formais. Nos clubes de ciências, as crianças são orientadas por um processo formal de pesquisa, que inclui a apresentação e divulgação dos resultados. Este documento descreve a metodologia de trabalho implementada com crianças de 4 a 12 anos, os atores, seus papéis e os produtos gerados ao longo dos 5 anos de sua implantação em comunidades urbanas e rurais no México. As experiências de trabalho em dois clubes de ciências são integradas. Com esse apoio, foi elaborado um guia de trabalho sistematizado para aprimorar a prática. Como parte da avaliação, foram realizadas entrevistas com as crianças participantes, que permitiram conhecer suas percepções sobre o trabalho que desenvolvem com elas, com o qual foi realizada uma análise descritiva das experiências. No ciclo de trabalho relatado, foram formadas cerca de 50 crianças, que tiveram um desempenho notável em concursos de ciências a nível nacional e internacional, o que lhes permitiu melhorar as suas competências investigativas, argumentativas e de resolução de problemas. O trabalho realizado tem permitido contribuir positivamente para as crenças das crianças, bem como a forma como estas apresentam propostas de soluções para os problemas, avaliam a qualidade das fontes e argumentam durante o desenvolvimento e apresentação dos trabalhos.

Palavras-chave: Clubes de ciência. Vocações científicas. Popularização. Formação científica. Crianças.

\section{INTRODUCCIÓN}

La ciencia y la tecnología han transformado el mundo en el que vivimos, debido a los avances la forma de realizar tareas cotidianas ha cambiado como por ejemplo, lavar la ropa se 
ha sofisticado en cuanto a la manera de llevar el agua a casa, el uso de detergentes con productos químicos, la producción de la energía para que la máquina lavadora funcione y hasta el mecanismo de secado se ha mecanizado. Se ha simplificado la tarea para el responsable de la limpieza, pero se han afectado al medio ambiente debido al uso excesivo de los recursos hídricos y su contaminación, y los altos consumos de energía. Lo anterior, abre discusiones acerca de los beneficios o perjuicios de la ciencia en el desarrollo de la humanidad. Son indiscutibles por ejemplo los beneficios que proporcionan los vehículos automotores a la sociedad, pero también es innegable su relación con el efecto invernadero y una de las principales causas de muerte en jóvenes (SUÁREZ, 2014).

Esta situación ha dividido las opiniones acerca de los beneficios de la ciencia. Los gobiernos y la comunidad científica, así como algunos miembros de la sociedad consideran a la ciencia y la educación como una forma de resolver los problemas de la sociedad moderna, en torno a la salud, producción de alimentos, economía, transporte, contaminación, etc. Sin embargo, hay un alto número de personas que muestran poco interés, e incluso aversión hacia los procesos científicos o manejan concepciones distintas al trabajo real de un investigador y su importancia (INEGI, 2017; FECYT, 2017). Según estudios hechos por la Fundación Española para la Ciencia y Tecnología (FECYT) el interés por la ciencia está en aumento (Figura 1A), aunque la inclinación por experimentar estas áreas por parte de las mujeres se sigue manteniendo por debajo del interés de los hombres, y al envejecer las personas dicha preferencia disminuye (Figura 2B).

En México, los intereses de la población se encuentran básicamente en los deportes y los problemas de contaminación ambiental, como se observa en la Figura 2. Estas concepciones tienen impacto en el número de estudiantes que egresan de carreras relacionadas con la Ciencia y la Tecnología en comparación con otras áreas del conocimiento, de acuerdo a la Red de Indicadores de Ciencia y Tecnología -Iberoamericana e Interamericana- (RICYT), las ciencias sociales continúan siendo las más elegidas por los estudiantes de grado en Iberoamérica, donde el 55\% de los titulados de grado en 2015 provenían de estas áreas (RICYT, 2017). Se considera que la educación científica no es exclusiva los estudiantes sino debe ser extendida a la ciudadanía (ACEVEDO, 2004). 


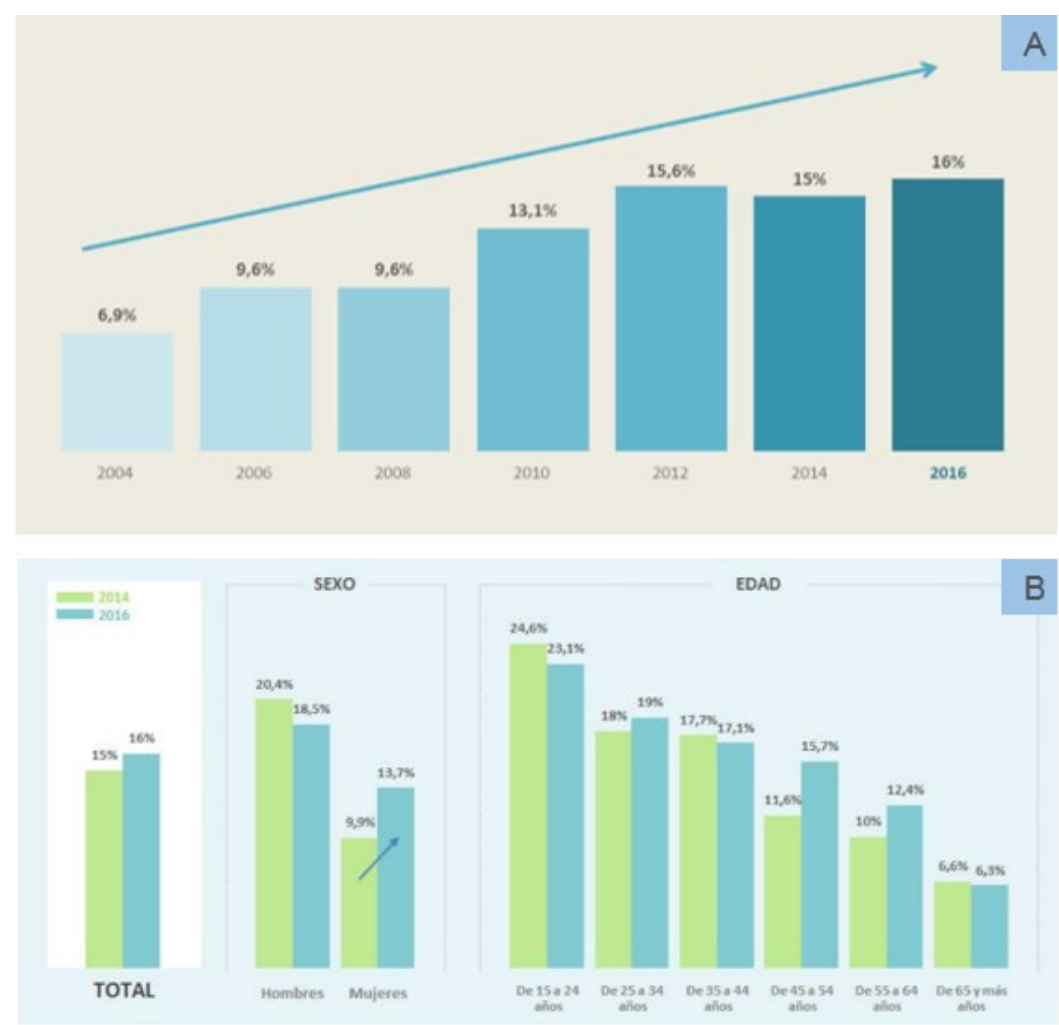

Figura 1 - Interés espontaneo por la ciencia y la tecnología A) Evolución de 2004 a 2016. B) Por rango de edad Fuente: VIII Encuesta de Percepción Social de la Ciencia y Tecnología. 2016. Fundación Española para la Ciencia y Tecnología. (FECYT) p. 3-4.

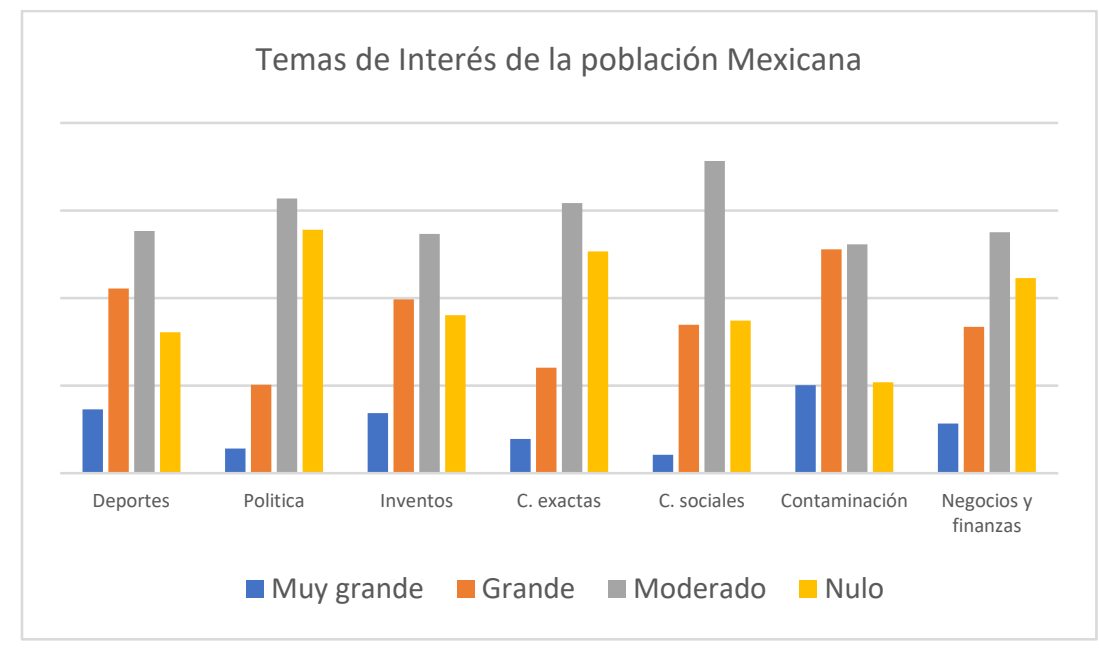

Figura 2 - Los intereses de la población mexicana

Fuente: Elaboración propia basada en CONACYT-INEGI, Encuesta sobre la Percepción Pública de la Ciencia y la Tecnología (ENPECYT) 2015 (INEGI, 2017).

En este contexto, la baja formación de científicos tiene impacto negativo en la generación de productos tecnológicos y de innovación, y por lo tanto en la economía, generando una dependencia tecnológica y económica de países más industrializados (COCA, VALERO y 
NASCIMENTO, 2014). Aunado a esto, se ha comprobado que la educación científica permite desarrollar capacidades, habilidades y actitudes que contribuyen a la formación de seres humanos críticos, reflexivos y responsables de lo que ocurre a su alrededor, conscientes de las problemáticas y dispuestos a trabajar en colectivo para proponer e implementar propuestas de solución (SANZ y LÓPEZ, 2012). Tales competencias científicas (DUSCHL, SCHWEINGRUBER y SHOUSE, 2007) requieren de la capacidad de usar e interpretar las explicaciones científicas en la solución de problemas y la comprensión del mundo real, entender la naturaleza y desarrollo del conocimiento científico para generar y evaluar explicaciones dadas por otros, comunicándose de una manera que sea consistente con las normas de la comunidad científica.

Se ha probado que la metodología STEM (por sus siglas en inglés Science, Technology, Engineering and Mathematics) permite trabajar un enfoque de enseñanza que promueve el interés de los estudiantes en carreras STEM y desarrollar habilidades conocidas que promueven el aprendizaje colaborativo y la indagación en contextos reales preparándolos para la toma de decisiones y solución de problemas en el área académica y vida cotidiana (MILLER, SONNERT y SADLER, 2018; SAHIN, AYAR y ADIGUZEL, 2014, LAPERTOSA, et al., 2017).

En México, se desea construir dentro de los escenarios formales de enseñanza tales habilidades cognitivas incluyéndose en los contenidos científicos curriculares de los programas educativos básicos (ACEVEDO, VÁZQUEZ, ACEVEDO y MANASSERO, 2002) y la propuesta de estrategias educativas innovadoras, siendo punto medular de la reforma de educación básica, se espera que:

\footnotetext{
los estudiantes "desarrollen habilidades asociadas al conocimiento científico y sus niveles de representación e interpretación acerca de los fenómenos naturales", ... "integren los conocimientos de las ciencias naturales a sus explicaciones sobre fenómenos y procesos naturales al aplicarlos en contextos y situaciones diversas" y... "reconozcan la ciencia como una actividad humana en permanente construcción, con alcances y limitaciones, cuyos productos son APROVECHADOS según la cultura y las necesidades de la sociedad" (SEP, 2011, p. 83).
}

En escenarios no formales de enseñanza y específicamente a través de actividades de divulgación se ha identificado la urgencia de contribuir a modificar aquellas creencias y concepciones erróneas hacia la ciencia y los científicos en niños y jóvenes, con el fin de despertar su interés hacia el trabajo científico, promoviendo la cultura científica para propiciar vocaciones, pero especialmente para la toma de decisiones responsables en el día a día. 
Dado este panorama las ferias de ciencias cobran vital importancia, por ser espacios donde se realiza exposición pública de trabajos científicos y tecnológicos desarrollados por niños y jóvenes, tanto en escenarios académicos (FERNÁNDEZ y SHAW, 2014; PETRINJAK, 2009) como los que no lo son (BIRCHER y SANSENBAUGHER 2015; SAHIN, 2013) y donde frecuentemente participan grupos de niños que han trabajado bajo la guía de un asesor, llamados Clubes de Ciencia.

Ha sido visto que en algunos contextos los estudiantes que han participado en actividades científicas incrementan su permanencia en la escuela (SAHIN, 2013). Permiten estudiar soluciones a problemas de la vida real (FERNÁNDEZ y SHAW 2014; SAHIN, 2013), promueven cambios conceptuales, mejoran las habilidades de razonamiento y argumentación de los estudiantes (KESELMAN et al., 2012), y las habilidades cognitivas de orden superior y de comunicación (SUÁREZ, OJEDA, MORA y MARTÍNEZ, 2013). Dentro de los clubes de ciencia se considera importante la planeación de los contenidos, que incluya la selección del conocimiento disciplinar y el contexto en el cual se va a presentar la problemática, así como y las habilidades a desarrollar por los estudiantes (SUÁREZ et al., 2016; VIEGAS, 2004).

La planeación del trabajo docente en escenarios académicos es de suma importancia, y una vez que se ha seleccionado el qué, se debe decidir el cómo, es decir la metodología, estrategia, recursos, entre otros. Campanario y Moya (1999) describen aspectos importantes dentro del proceso como son: a) plantear situaciones problemáticas acordes a los intereses de los niños, b) hacer una descripción cualitativa de la situación y reforzar con información obtenida en la bibliografía para facilitar el planteamiento de objetivos, c) estudiar el problema bajo un enfoque basado en el método científico, d) utilizar los conocimientos nuevos para la generación de propuestas de solución.

Con esta base se ha diseñado una metodología que ha sido implementada en niños y jóvenes, con el fin de promover una cultura científica y el gusto por la ciencia, a partir del desarrollo de proyectos científicos que posteriormente se someterán a concurso y exposición en ferias científicas. En este trabajo se muestra una descripción de las actividades a cinco años de desarrollo de la estrategia, se presentan los actores y su participación en los clubes de ciencia así como la presentación de un caso de éxito entre los estudiantes. 


\section{FASES DE TRABAJO DENTRO DE LOS CLUBES DE CIENCIA}

La metodología aquí propuesta se ha desarrollado en el seno de los clubes de Ciencia "Nikola Tesla", "Ciencia en Contexto" y "Escuela de Pequeños Ingenieros, A.C", el primero ubicado en la ciudad de San Luis Potosí y los siguientes en el Municipio de Tamazunchale, en el estado Mexicano de San Luis Potosí. Los clubes de ciencias son miembros de la Red de divulgación de la Ciencia, Tecnología e Innovación, REDICITI del Consejo Potosino de Ciencia y Tecnología, de la Red Nacional de Actividades Juveniles en Ciencia y Tecnología de Milset y de la Red Iberoaméricana de Clubes de Ciencias.

Durante un periodo de seis años se ha guiado a niños que integran los clubes a la construcción de diferentes proyectos a través de talleres científicos, los cuales se llevan a cabo extracurricularmente, en sesiones vespertinas y/o sabatinas, cubriendo un total de 4 horas presenciales por semana y 2 horas de actividades de lectura, investigación y elaboración de prototipos para trabajo en casa.

Los niños son invitados a través de convocatorias abiertas realizadas en las instituciones educativas, redes sociales y medios masivos de información como periódicos, radio y televisión. Los padres de familia y niños interesados realizan su inscripción al club de ciencias en las instalaciones donde se llevan a cabo las actividades.

\subsection{Descripción de los equipos colaborativos}

Los grupos de clase son de máximo 12 integrantes y están bajo la asesoría de al menos un profesor con formación disciplinar en un área de las ciencias, y con el apoyo de expertos disciplinares y/o pedagógicos.

Los alumnos se integran por grupos de edades de acuerdo al siguiente criterio: Categoría petit: de 5 a 7 años, categoría kids: de 8 a 11 años y categoría juvenil: 12 a 15 años. Esta clasificación se basa en la sugerida por el Movimiento Internacional de Recreo Científico y Tecnológico (MILSET por sus siglas en francés). El número de integrantes de los equipos es de tres niños como máximo, con edades similares, pero de ser posible, de diferentes habilidades para que puedan atender a varios aspectos del proyecto y unos aprendan de otros. Cada equipo colaborativo estará bajo la asesoría de un profesor responsable y trabajará a su propio ritmo de acuerdo a sus intereses y capacidades. 


\subsection{Selección de los temas de investigación}

Desde la creación de los clubes de ciencia, se han atendido en los proyectos, temas de diversas áreas del conocimiento, basándose en la metodología de investigación científica y con atención a una problemática y contexto en particular. El punto de inicio del trabajo de investigación es siempre a partir de una pregunta planteada por el niño. El desarrollo del proyecto se realiza en varias sesiones, de acuerdo a la profundidad de la investigación y la edad de los participantes, siempre bajo el esquema descrito a continuación.

Paso 1. Planteamiento. En las primeras dos sesiones se proponen situaciones donde se promueva la discusión de la problemática general observada por los niños, tratando de inducirlos a elaborar preguntas al respecto. Como fijador del conocimiento, las propuestas de solución pueden dibujarse, escribirse, o modelarse en plastilina. Estas experiencias sirven como una introducción al proceso de investigación bajo el método científico y le permite al pequeño relacionarse con el vocabulario y metodología de trabajo.

Paso 2. Delimitación del tema. En este paso se han identificado dos opciones, en la primera el alumno ya sabe qué tema desea estudiar. Bajo este esquema, es importante que el asesor tenga la disposición de buscar la mayor cantidad de información relacionada y la forma de abordar el problema y de ser necesario consultarlo con expertos. La segunda opción, implica que el asesor plantee varios proyectos al alumno, para esto deberá dedicarse una sesión a conocer los intereses del niño; una vez que se selecciona, el asesor expondrá la problemática de manera tal que despierte el interés del niño sobre el problema de estudio, hasta que este tenga la capacidad de proponer una pregunta específica.

Paso 3. El desarrollo del proyecto. Una pieza clave en el éxito del proyecto, es la capacidad del asesor para guiar a los niños a delimitar el tema sin que se limite su curiosidad. Es de suma importancia conducir los intereses de los niños al desarrollo de un proyecto viable. Acotar objetivos de acuerdo a tiempos establecidos ayudará a que el niño mantenga el interés, graduando el nivel de complejidad, que plantee retos pero que los mismos sean alcanzables, se pueden dar ayudas o tips pero nunca realizar las tareas por ellos. Para el desarrollo de la investigación se sugiere un tiempo máximo de cuatro meses, se ha observado que en proyectos que se extienden más allá de ese tiempo se dificulta mantener el interés en el niño. En este punto, el guía o asesor, deberá elaborar una secuencia didáctica por proyecto, que indique las competencias a desarrollar por los niños, a partir de las características propias de cada grupo de 
estudiantes. Es importante considerar que las actividades puedan ser modificadas por los niños para favorecer el desarrollo de su creatividad y del pensamiento crítico.

De igual manera, es recomendable que el profesor haya realizado los experimentos, proyectos, trabajos con anterioridad; y de preferencia, que hayan sido discutidos con expertos de las disciplinas involucradas, para poder guiar a los niños en las preguntas que surjan durante la puesta en marcha. Nunca un experimento o sesión debe dejarse sin una explicación de los resultados, la cual puede partir del profesor, pero buscando que el niño genere sus propias conclusiones. Hay que recordar que el trabajo científico está en la búsqueda de explicaciones basadas en hechos.

Se espera que al término el proyecto sea presentado en alguna feria de ciencias o escenario de divulgación que puede ser incluso su propia escuela frente a sus compañeros.

No existe una memorización de la exposición, los niños deben evidenciar que pueden construir explicaciones y dar respuesta a las preguntas de los asistentes o en su caso jueces, si se les pregunta algo poco relacionadas con el tema, los niños deben desarrollar la capacidad de generar respuestas y sus propias conclusiones.

\subsection{Recomendaciones}

Para que el asesor del proyecto guíe al alumno en el proceso de investigación, se dan las siguientes recomendaciones:

a) Al trabajar con niños de categoría petit (3 a 7 años), el asesor deberá realizar la investigación del tema y durante varias sesiones ejemplificar el material a los niños. Se sugiere utilizar como apoyo dibujos, rompecabezas y material didáctico.

b) En el caso de estudiantes de categoría kids ( 8 a 12 años), el proceso de investigación bibliográfica podrá hacerse de manera compartida, dejando que los alumnos seleccionen algunas fuentes de información, pero guiándolos en todo momento en el proceso; se recomienda acercar libros, revistas manuales, $\mathrm{u}$ otras fuentes diferentes a la consulta en internet, aunque también pueden iniciarse en el uso de bases de datos, o buscadores como Wólfram Alfa o Google Académico, entre otros. Esta etapa permite que los estudiantes trabajen la parte del sustento de las ideas y se inicie con el desarrollo de habilidades cognitivas necesarias para la argumentación.

c) Para estudiantes de secundaria y grados mayores (categoría juvenil), el alumno deberá ser capaz de hacer el planteamiento de la experimentación, así como la búsqueda 
bibliográfica, siempre bajo la supervisión del asesor, pero aumentando el rigor de la misma. Es importante promover la elaboración de fichas bibliográficas ya sea electrónicas o en papel, y preferentemente bajo un formato de referencias (puede apoyarse en la herramienta contenida en el editor de textos de Microsoft).

d) La edad marca la pauta a seguir en el proceso de investigación y experimentación. Para los más pequeños se sugiere apoyarse de dibujos en un portafolio, cartulinas, hojas, maquetas, u organizadores gráficos. El grado de formalidad de la investigación podrá ir aumentando conforme a la edad y/o experiencia en el trabajo, esto permite que el niño se sienta a gusto en el proceso.

\subsection{Bitácora}

Durante las 16 semanas sugeridas para la realización de los proyectos, el trabajo elaborado en cada sesión debe plasmarse en una bitácora, donde registren sus resultados. Los niños esperan ciertos resultados los cuales clasifican como "buenos resultados" y a cosas que no esperaban encontrar como "malos resultados", esta creencia se ha visto extendida en los niños, por lo que con el uso de la bitácora se busca, además de mantener un orden en el proyecto, modificar estas creencias. Las ideas que surgen y sus planteamientos, información consultada, bosquejos, facilitan el seguimiento del desarrollo del proyecto, y al finalizar poder interpretar resultados y generar reportes. Cuando los niños se integran a los talleres, se les proporciona una guía de trabajo que deben llenar conforme avanzan en sus propuestas. Un ejemplo de una bitácora es mostrado en la Figura 3. Se ha visto que el uso de la bitácora facilita retomar el trabajo por los niños y dar seguimiento a las actividades, así mismo promueve la escritura y la organización de la información. Las bitácoras también son útiles como evidencia del trabajo realizado dentro de los concursos de ciencia. 

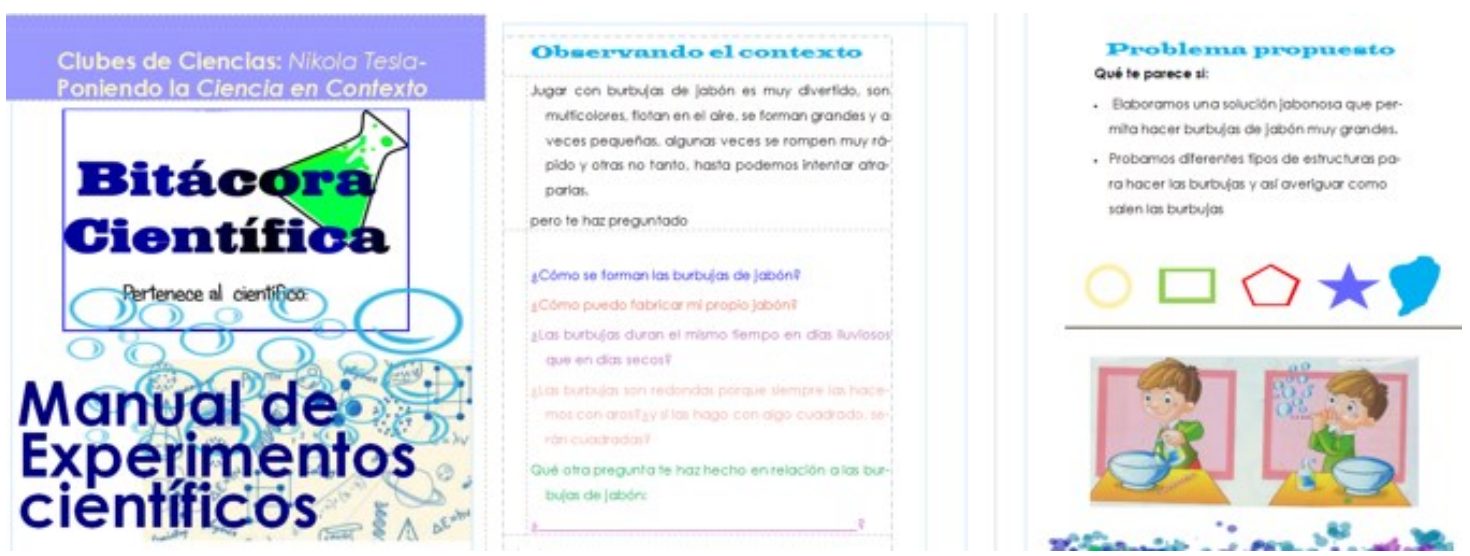

Figura 3 - Bitácora del taller "Educando al científico que llevamos dentro", donde se presentan los pasos del método científico a los asistentes en los talleres

Fuente: Elaboración propia de los autores.

\subsection{La planeación didáctica}

Una vez que los estudiantes han seleccionado el tema a desarrollar, el asesor elabora una tabla descriptiva donde se incluyen los aspectos a incluir en la secuencia didáctica, lo cual facilita el seguimiento del proyecto, especialmente cuando se asesora simultáneamente a más de un equipo y que abordan temáticas diferentes.

Tabla 1 - Consideraciones para la elaboración de la secuencia didáctica del proyecto generado dentro del taller de ciencias.

\begin{tabular}{|l|l|}
\hline $\begin{array}{l}\text { Selección del tema } \\
\text { principal }\end{array}$ & Propuesto por los niños o el asesor \\
\hline $\begin{array}{l}\text { Identificación de los } \\
\text { componentes de las } \\
\text { competencias a } \\
\text { desarrollar por el niño de } \\
\text { acuerdo a la perspectiva } \\
\text { del asesor. }\end{array}$ & $\begin{array}{l}\text { Habilidades investigativas: Planteamiento de preguntas y propuestas de } \\
\text { solución, mecanismos de búsqueda de información, planteamiento de objetivos, } \\
\text { diseño de actividades experimentales, diseño y elaboración de materiales, } \\
\text { de las propuestas basadas en los resultados. } \\
\text { Conceptos Científicos: De acuerdo a la problemática seleccionada el profesor } \\
\text { identifica el nivel de conocimiento, edad e intereses de los niños, así mismo, } \\
\text { realiza un mapeo de contenidos relacionados al tema y elabora una guía de } \\
\text { avance para facilitar el seguimiento en el estudiante y las actividades propuestas. } \\
\text { Conocimientos adicionales: Uso de software, herramientas, carpintería, etc. } \\
\text { requeridos para llevar a buen término la conclusión del proyecto. }\end{array}$ \\
\hline
\end{tabular}




\begin{tabular}{|l|l|} 
Tareas del profesor & $\begin{array}{l}\text { Elaboración de la secuencia didáctica: Propone las actividades iniciales y da } \\
\text { seguimiento al desarrollo de las mismas, alerta de hacer las adecuaciones } \\
\text { necesarias de acuerdo al desarrollo del proyecto. } \\
\text { Redacción de textos científicos: Apoya en la elaboración del reporte de } \\
\text { investigación. } \\
\text { Comunicación de resultados: Da seguimiento a las presentaciones orales de los } \\
\text { niños. } \\
\text { Evaluación y seguimiento de actividades: Lleva a cabo el registro de asistencia } \\
\text { de los niños, monitorea el avance en los conocimientos y habilidades, } \\
\text { utilizando una lista de cotejo o una rúbrica de evaluación preferentemente al } \\
\text { término de fase del proyecto. } \\
\text { Participación en eventos académicos: Busca escenarios para divulgar los } \\
\text { resultados. Revisión de convocatorias, selección de los niños de acuerdo a su } \\
\text { perfil e intereses, inscribir a los niños a los eventos previa recopilación de los } \\
\text { documentos solicitados en la convocatoria. }\end{array}$ \\
\hline Tareas del alumno & $\begin{array}{l}\text { Desarrollar los proyectos de acuerdo a la guía del profesor, preparar la } \\
\text { presentación del proyecto, llevar a cabo los experimentos, elaboración de } \\
\text { materiales, investigación y preparación de las exposiciones. }\end{array}$ \\
\hline $\begin{array}{l}\text { Tareas de los padres de } \\
\text { familia }\end{array}$ & $\begin{array}{l}\text { Realizar un acompañamiento de los menores durante el desarrollo del } \\
\text { proyecto, asistir al menos a una exposición de trabajos y cuando sea necesario } \\
\text { acompañar a los menores a los eventos académicos y ferias de ciencia, cubrir } \\
\text { los costos de viajes y materiales si así se requiere. }\end{array}$ \\
\hline
\end{tabular}

Fuente: Elaboración propia de los autores.

\subsection{Presentación de resultados de los proyectos}

Todo trabajo de investigación debe ser acompañado por un reporte que informe los resultados obtenidos en la investigación. El formato del documento lleva los apartados de cualquier artículo de investigación, esto es, introducción, metodología, presentación de resultados, discusión, conclusiones y referencias. Este documento se trabaja en conjunto con los alumnos variando el grado de involucramiento; conforme los alumnos van adquiriendo experiencia la aportación de los asesores disminuye.

El ciclo de trabajo deberá cerrarse con la exposición del proyecto y sus resultados. Se sugiere hacerlo en concursos de ciencias, encuentros de investigación, ferias de ciencias, foros, etc., ya que son el lugar donde los niños pueden mejorar sus capacidades de expresión oral. En este punto, los niños dejan de ser aprendices para convertirse en divulgadores.

Previamente, se sugiere realizar presentaciones de avance de forma periódica: al término de las sesiones propuestas por el asesor se invitarán a otros niños fuera del grupo de trabajo, padres de familia, etc., para ir favoreciendo las habilidades de comunicación de los niños. 


\section{DESCRIPCIÓN Y VALORACIÓN DE LA EXPERIENCIA}

La metodología antes presentada busca la formación de ciudadanos críticos, que sean capaces de encontrar soluciones a problemas específicos del entorno. Desde el 2011 se han asesorado aproximadamente 25 proyectos, con los cuales han participado en concursos de ciencia y otros eventos de divulgación, obteniendo lugares a nivel local, estatal, nacional e internacional e impartiendo talleres para compartir su aprendizaje con otros niños. A continuación, se describen a manera de ejemplo algunos proyectos realizados.

Los cuatro elementos (2012). Niño “D”, edad 7 años. Objetivo: Desarrollar un videojuego ecocultural que muestra cómo ayudar a limpiar el planeta. Aprendizajes esperados: Aprenden diseño de videojuegos; se promueve la creatividad e independencia en el diseño de sus algoritmos.

Érase una vez una mariposa (2014). Niñas "D" y "E", edad 4 y 6 años. Objetivo: Aprender del ciclo de vida de las mariposas. Aprendizajes esperados: A través de videos y lecturas se busca que las niñas reconozcan la importancia del cuidado de las mariposas como medida de cuidado del entorno ecológico. Elaboran una bitácora a partir de dibujos que les permiten llevar la secuencia de sus actividades. Desarrollan materiales para explicar su ciclo de vida y para compartir con otros su conocimiento.

Riqueza de la biodiversidad de la Huasteca Potosina (2016). Niño “JS”. edad 10 años. Objetivo: Identificar aspectos de la biodiversidad de la Huasteca Sur a través de un recorrido en las pozas de San Miguel. Aprendizajes esperados: A partir de un recorrido hacia las pozas se identifican aspectos como plantas, frutos, hojas, raíces, que conforman el medio ambiente y sus usos por los pobladores como plantas medicinales, a través de la recuperación de conocimientos de los habitantes, con esa información se elaboran videos y materiales que permiten dar a conocer a otros niños y población en general los conocimientos adquiridos. El niño evidenció una mejora en las habilidades de comunicación, organización de la información y apropiación de los conocimientos adquiridos.

Aprender de insectos es divertido (2014). "J" y "P" de 8 años de edad. Reconocer la importancia de los insectos en el medio ambiente, apreciar su diversidad y su relación con la transmisión de enfermedades tropicales transmitidas por vector. Aprenden sobre los insectos, su importancia, características, funciones en el medio ambiente, como elaborar trampas, recolectan insectos, elaboran una colección entomológica, realizan la catalogación, hacen $\underline{\text { experimentos para identificar como repelerlos para evitar el uso de insecticidas y no matarlos, }}$ 
además, elaboraron un libro electrónico usando un software libre con lo aprendido para compartir con otros a través de un taller de divulgación científica. Su acercamiento con expertos disciplinares (entomólogos, bioquímicos, físicos) favoreció el conocimiento del método científico, el uso de la bitácora y la importancia de la experimentación y la comunicación de los resultados.

Para realizar una descripción más detallada del trabajo realizado se ejemplifica con el proyecto "Aprender de insectos es divertido", cuya secuencia didáctica se muestra en la tabla 2 y las imágenes de los niños trabajando en la Figura 4. Con este proyecto participaron en el Concurso Expociencias a nivel local, obteniendo acreditaciones para la etapa estatal y nacional, durante ese tiempo tuvieron reuniones periódicas de avances. También, presentaron su trabajo en el Primer encuentro de niños investigadores de Tamazunchale, en la XXI Semana Nacional de Ciencia y Tecnología de la Universidad Autónoma de San Luis Potosí y en el encuentro de niños sobresalientes del Estado de San Luis Potosí. Han participado en el Concurso Pauling de Ciencias obteniendo lugar en la categoría de ciencias y filosofía. Han seguido participando en otros proyectos que les permitió una vez más llegar al Nacional en 2016.

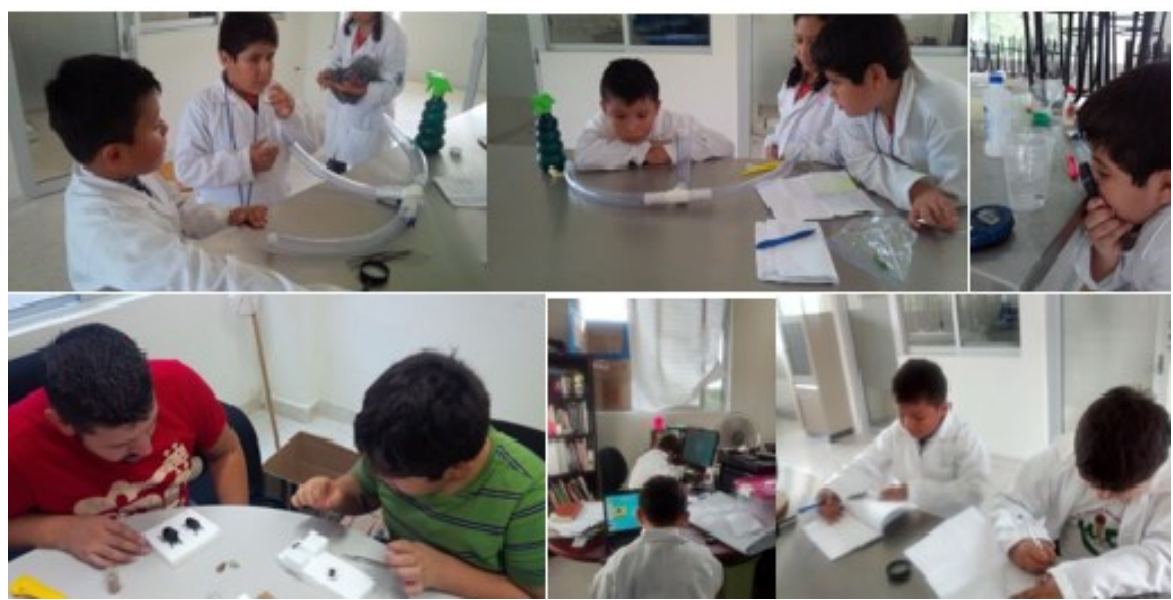

Figura 4 - Trabajo de los niños en actividades de aprendizaje: Aprender de insectos es divertido. Fuente: Elaboración propia de los autores.

Tabla 2 - Secuencia Didáctica del proyecto “Aprender de insectos es divertido" (2014).

\begin{tabular}{|l|l|l|}
\hline Aprender de insectos es divertido & Tema: La importancia de los insectos en el medio ambiente \\
\hline Nivel Taxonomía SOLO: Abstracto & Objetivos: Describir las características de & $\begin{array}{l}\text { Habilidades } \\
\text { cognitivas: }\end{array}$ \\
Ampliado. & los insectos. & $\begin{array}{l}\text { Pensamiento } \\
\text { Usa un principio general y abstracto producto }\end{array}$ \\
de su análisis y lo puede generalizar a otros & el medio ambiente. & crítico. \\
contextos. Capaz de hacer hipótesis basadas & Identificar los beneficios de los insectos en & \\
en principios generales (BIGGS, 2006; & el medio ambiente. & \\
BIGGS y COLLINS, 1982). & & \\
\hline
\end{tabular}




\begin{tabular}{|c|c|c|c|c|c|}
\hline & & $\begin{array}{l}\text { Elaborar una colección entomológica } \\
\text { se relacione los niveles taxonómicos }\end{array}$ & & & \\
\hline Recurso: Taller "Los & nsectos" & & & & $\begin{array}{l}\text { "Ciencia en } \\
\text { Contexto" }\end{array}$ \\
\hline $\begin{array}{l}\text { Descripción de la } \\
\text { estratégia. }\end{array}$ & ¿Qué hace el profesor? & ¿Qué hace el estudiante? & $\begin{array}{l}\text { Ano } \\
\text { com }\end{array}$ & & $\begin{array}{l}\text { nes } \\
\text { entarias }\end{array}$ \\
\hline $\begin{array}{l}\text { Contextualización y } \\
\text { reconocimiento de } \\
\text { ideas previas. }\end{array}$ & $\begin{array}{l}\text { Taller: } \\
\text { Se presenta una imagen } \\
\text { con diferentes } \\
\text { animales, insectos, } \\
\text { arácnidos, reptiles, se } \\
\text { les pregunta a los niños } \\
\text { ¿Cuáles de ellos son } \\
\text { insectos? }\end{array}$ & $\begin{array}{l}\text { Explicita lo que sabe seleccionando } \\
\text { incisos que considera que son insecto }\end{array}$ & & & $\begin{array}{l}\text { identifica las } \\
\text { racterísticas de } \\
\text { insectos }\end{array}$ \\
\hline $\begin{array}{l}\text { Gestión de los } \\
\text { materiales de } \\
\text { aprendizaje. }\end{array}$ & $\begin{array}{l}\text { Se trabaja con una } \\
\text { clase magistral } \\
\text { impartida por un } \\
\text { entomólogo, utilizando } \\
\text { como recurso una } \\
\text { presentación en power } \\
\text { point donde se } \\
\text { describen las } \\
\text { características de los } \\
\text { insectos, sus partes y la } \\
\text { importancia para la } \\
\text { vida. La diferencia } \\
\text { entre insectos y plagas. } \\
\text { También se determina } \\
\text { donde viven, que } \\
\text { comen, se hace énfasis } \\
\text { en que es preferible } \\
\text { alejarlos que matarlos. } \\
\text { como atraparlos (para } \\
\text { fines de investigación) } \\
\text { como elaborar trampas }\end{array}$ & $\begin{array}{l}\text { El estudiante participa en la clase } \\
\text { haciendo preguntas y siguiendo las } \\
\text { indicaciones del ponente. }\end{array}$ & & & \\
\hline $\begin{array}{l}\text { Verificación de } \\
\text { comprensión de la } \\
\text { actividad de } \\
\text { introducción }\end{array}$ & $\begin{array}{l}\text { Se le solicita al } \\
\text { estudiante que colecte } \\
\text { insectos que encuentre } \\
\text { en su casa, escuela, } \\
\text { comunidad en general, } \\
\text { utilizando una de las } \\
\text { trampas mostradas } \\
\text { dependiendo si es para } \\
\text { aire, agua o tierra. } \\
\text { Determine donde } \\
\text { fueron colectados los } \\
\text { insectos y describa que } \\
\text { tipo de insecto es. }\end{array}$ & $\begin{array}{l}\text { Elabora una trampa de acuerdo al tip } \\
\text { de insecto que desea atrapar. } \\
\text { Colecta el insecto y lo transporta a la } \\
\text { escuela. } \\
\text { Escribe una ficha de identificación d } \\
\text { insecto, incluyendo lo que sabe y/o h } \\
\text { investigado sobre él. }\end{array}$ & & & $\begin{array}{l}\text { s estudiantes } \\
\text { án lo posible } \\
\text { llevar a os } \\
\text { ectos vivos a } \\
\text { escuela y } \\
\text { scribe lo que } \\
\text { e sobre ese } \\
\text { ecto. }\end{array}$ \\
\hline $\begin{array}{l}\text { Confrontación de } \\
\text { las ideas de los } \\
\text { estudiantes }\end{array}$ & $\begin{array}{l}\text { El día señalado se hace } \\
\text { la colecta de los } \\
\text { estudiantes, colocando } \\
\text { los botes con los } \\
\text { insectos a la vista de } \\
\text { todos, se describe lo } \\
\text { que han puesto y el } \\
\text { entomólogo y su } \\
\text { equipo ayuda a } \\
\text { identificar errores en }\end{array}$ & $\begin{array}{l}\text { En plenaria los estudiantes expondrá } \\
\text { sus hallazgos, reafirmando su } \\
\text { conocimiento y/o reconociendo los } \\
\text { posibles errores }\end{array}$ & & & $\begin{array}{l}\text { gran } \\
\text { ntificar } \\
\text { acterísticas de } \\
\text { insectos, los } \\
\text { mbres que } \\
\text { hen, los riesgos } \\
\text { a la salud. }\end{array}$ \\
\hline
\end{tabular}




\begin{tabular}{|c|c|c|c|}
\hline & $\begin{array}{l}\text { los niños acerca de lo } \\
\text { que han escrito, se } \\
\text { comparte en } \\
\text { conocimiento. }\end{array}$ & & \\
\hline $\begin{array}{l}\text { Trabajo con el } \\
\text { contexto }\end{array}$ & $\begin{array}{l}\text { El profesor forma el } \\
\text { equipo colaborativo. } \\
\text { Guía a un grupo de } \\
\text { niños para que sean } \\
\text { capaces de: } \\
\text { Clasificar los insectos } \\
\text { colectados por el } \\
\text { colectivo, identificando } \\
\text { sus partes, medio, etc. } \\
\text { Organizar en } \\
\text { recipientes los insectos } \\
\text { de acuerdo a sus } \\
\text { características, } \\
\text { selección a los más } \\
\text { preservados para su } \\
\text { inclusión en la } \\
\text { colección } \\
\text { entomológica. } \\
\text { Bajo instrucción guiada } \\
\text { muestran a los } \\
\text { estudiantes como secar } \\
\text { los insectos y } \\
\text { prepararlos para su } \\
\text { montaje. }\end{array}$ & $\begin{array}{l}\text { Los niños del equipo colaboran con el } \\
\text { grupo de trabajo del entomólogo, } \\
\text { organizando, clasificando y etiquetando } \\
\text { a los insectos que formaran parte de la } \\
\text { colección. } \\
\text { Colectan insectos en sesiones nocturnas } \\
\text { y diurnas en áreas rurales para } \\
\text { complementar la colección. } \\
\text { Leen utilizando ligas de internet la } \\
\text { información sobre las taxonomías de } \\
\text { los insectos y guiados bajo la asesoría } \\
\text { del entomólogo elaboran la ficha } \\
\text { taxonómica de los insectos colectados. }\end{array}$ & $\begin{array}{l}\text { Los estudiantes } \\
\text { compartirán sus } \\
\text { conocimientos } \\
\text { acerca del tema, } \\
\text { desarrollan } \\
\text { habilidades para } \\
\text { matar, disecar y } \\
\text { organizar los } \\
\text { insectos y la } \\
\text { información } \\
\text { referente a las } \\
\text { fichas que será } \\
\text { expuesta en la } \\
\text { colección } \\
\text { entomológica. }\end{array}$ \\
\hline Metacognición & $\begin{array}{l}\text { Formula preguntas que } \\
\text { van a ayudar a los } \\
\text { estudiantes a elaborar } \\
\text { la colección } \\
\text { entomológica y realizar } \\
\text { contrastaciones con la } \\
\text { información } \\
\text { investigada en los } \\
\text { medios impresos y } \\
\text { virtuales. }\end{array}$ & $\begin{array}{l}\text { Realiza las actividades solicitadas por } \\
\text { el profesor, participa activamente en el } \\
\text { montaje de la colección. }\end{array}$ & $\begin{array}{l}\text { Realizan } \\
\text { discusiones } \\
\text { periódicas con las } \\
\text { investigadoras a } \\
\text { cargo del } \\
\text { proyecto. }\end{array}$ \\
\hline $\begin{array}{l}\text { Experimentación y } \\
\text { Formalización } \\
\text { conceptual. } \\
\text { Construcción de } \\
\text { explicaciones }\end{array}$ & $\begin{array}{l}\text { Inicia el montaje de los } \\
\text { insectos, colocando las } \\
\text { fichas de clasificación. }\end{array}$ & $\begin{array}{l}\text { Colabora en la construcción de la } \\
\text { colección entomológica }\end{array}$ & $\begin{array}{l}\text { Utiliza } \\
\text { herramientas, } \\
\text { desarrolla } \\
\text { destrezas de } \\
\text { motricidad fina. }\end{array}$ \\
\hline $\begin{array}{l}\text { Socialización del } \\
\text { trabajo }\end{array}$ & $\begin{array}{l}\text { Guía al alumno } \\
\text { identificar los aspectos } \\
\text { relevantes de la } \\
\text { investigación para que } \\
\text { el niño los plasme en el } \\
\text { reporte. }\end{array}$ & $\begin{array}{l}\text { Participa activamente en la escritura del } \\
\text { documento y los materiales para su } \\
\text { divulgación. }\end{array}$ & $\begin{array}{l}\text { Durante la } \\
\text { escritura práctica } \\
\text { sobre las ideas } \\
\text { para la } \\
\text { exposición. }\end{array}$ \\
\hline $\begin{array}{l}\text { Consolidación. } \\
\text { Aplicación de los } \\
\text { modelos } \\
\text { construidos: } \\
\text { Aplicaciones a } \\
\text { problemas } \\
\text { similares. }\end{array}$ & $\begin{array}{l}\text { Explica el uso del } \\
\text { software para elaborar } \\
\text { libros interactivos, } \\
\text { ejemplifica como subir } \\
\text { imágenes, audio, } \\
\text { elaborar actividades de } \\
\text { aprendizaje. }\end{array}$ & $\begin{array}{l}\text { Elabora un libro electrónico de al } \\
\text { menos diez hojas que contengan la } \\
\text { información relevante en torno a los } \\
\text { insectos y los resultados de la } \\
\text { investigación. }\end{array}$ & $\begin{array}{l}\text { Durante el trabajo } \\
\text { en el aula se } \\
\text { podrán utilizar } \\
\text { materiales } \\
\text { diversos de } \\
\text { consulta para } \\
\text { obtener } \\
\text { información } \\
\text { necesaria para la }\end{array}$ \\
\hline
\end{tabular}




\begin{tabular}{|c|c|c|c|}
\hline & & & $\begin{array}{l}\text { elaboración de } \\
\text { sus propuestas. }\end{array}$ \\
\hline $\begin{array}{l}\text { Consolidación. } \\
\text { Aplicación de los } \\
\text { modelos } \\
\text { construidos: } \\
\text { Aplicaciones de } \\
\text { transferencia a otros } \\
\text { contextos. }\end{array}$ & $\begin{array}{l}\text { Se plantean situaciones } \\
\text { que permitan realizar } \\
\text { diseños experimentales } \\
\text { con base en las } \\
\text { pregunta: } \\
\text { 1. ¿Cómo podemos } \\
\text { exterminar de nuestras } \\
\text { casas los insectos plaga } \\
\text { sin utilizar insecticidas } \\
\text { ni pesticidas? } \\
\text { 2. ¿Si los insectos son } \\
\text { necesarios para el } \\
\text { medio ambiente como } \\
\text { podemos alejarlos de } \\
\text { nuestra casa en lugar } \\
\text { de exterminaros? } \\
\text { Modera una discusión } \\
\text { acerca de cómo } \\
\text { proponer experimentos } \\
\text { que nos lleven a } \\
\text { responder las } \\
\text { preguntas. } \\
\text { Acompaña a los niños } \\
\text { durante las sesiones } \\
\text { experimentales. }\end{array}$ & $\begin{array}{l}\text { Propone ideas, materiales, métodos } \\
\text { para realizar los experimentos y los } \\
\text { lleva a cabo. } \\
\text { Para contestar la pregunta } 1 \text { colecta } \\
\text { insectos, los expone a diferentes } \\
\text { líquidos que se encuentran el hogar, } \\
\text { detergente, limpiadores, vinagre, etc. } \\
\text { Observa e identifica si muere y de ser } \\
\text { así el tiempo que le toma. } \\
\text { Para la pregunta } 2 \text { diseña una trampa, } \\
\text { hace que los insectos entren a la trampa } \\
\text { y observa hacia donde se dirigen, el } \\
\text { objetivo es identificar olores o } \\
\text { sustancias que los atraigan y/o alejen. }\end{array}$ & $\begin{array}{l}\text { Realizan las } \\
\text { actividades } \\
\text { experimentales } \\
\text { manteniendo en } \\
\text { la medida de lo } \\
\text { posible las } \\
\text { normas de uso de } \\
\text { los laboratorios. } \\
\text { Aprende sobre la } \\
\text { importancia de } \\
\text { las mediciones y } \\
\text { de los } \\
\text { instrumentos, } \\
\text { recabar datos, } \\
\text { realizar el } \\
\text { reporte, y } \\
\text { presentar la } \\
\text { información } \\
\text { adecuadamente. }\end{array}$ \\
\hline $\begin{array}{l}\text { Estrategia de } \\
\text { evaluación }\end{array}$ & \multicolumn{3}{|c|}{$\begin{array}{l}\text { La información utilizada en el libro electrónico ayuda a identificar los aprendizajes } \\
\text { obtenidos y las concepciones erróneas, las preguntas que plantean y las respuestas que } \\
\text { dan, permite dar seguimiento a los aprendizajes. Durante la presentación de los temas, } \\
\text { se evalúa además de la exposición la respuesta a las preguntas de los jueces y } \\
\text { asistentes al evento. Al término de cada exposición discuten con el asesor las dudas } \\
\text { generadas y/o el interés por alguna pregunta que se les haya realizado. }\end{array}$} \\
\hline $\begin{array}{l}\text { Criterios de } \\
\text { evaluación }\end{array}$ & \multicolumn{3}{|c|}{$\begin{array}{l}\text { Se valoran los conocimientos adquiridos en torno a los insectos, sus partes, tipos de } \\
\text { insectos, su función en la naturaleza, su hábitat y lo que aparece en la ficha de taxón. } \\
\text { Habilidades para el uso de las herramientas del montaje de la colección. } \\
\text { Manejo del software. } \\
\text { Habilidades de investigación y experimentales } \\
\text { Habilidades de comunicación. }\end{array}$} \\
\hline $\begin{array}{l}\text { Trabajo en otros } \\
\text { escenarios } \\
\text { académicos }\end{array}$ & \multicolumn{3}{|c|}{ Presentan sus resultados en diferentes escenarios académicos. } \\
\hline Notas del profesor & \multicolumn{3}{|c|}{$\begin{array}{l}\text { Los niños presentan interés por desarrollar repelentes de insectos a partir de plantas de } \\
\text { la región huasteca como es el neem y la limonaria. }\end{array}$} \\
\hline
\end{tabular}

Fuente: Elaboración propia de los autores.

Es evidente para estos dos niños el impacto en los trabajos de ciencia, al ser informados por ejemplo de que un alimento no es muy saludable, un diálogo real entre uno de éstos niños y su mamá.

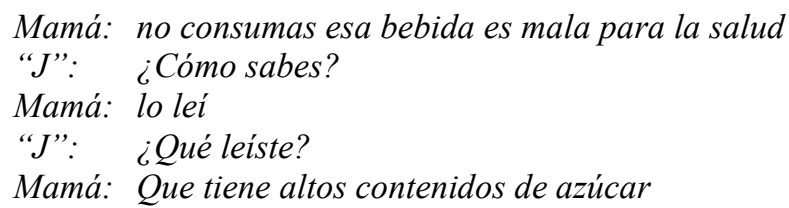


"J": ¿Dónde lo leiste?

Mamá: En un artículo de investigación

"J”: ¿Quién lo escribió?

Mamá: Un científico de la UNAM

"J": Mmm, ;ah! UNAM, ¿Esa universidad es buena no? Entonces ese científico debe ser bueno, Joel, --voltea dirigiéndose a su amigo -Ya no consumas esa bebida mi mama leyó en una revista que tiene mucha azúcar y no es saludable.

(Diálogo entre tutor y alumno, 2017).

Este diálogo entre los niños asistentes al taller muestra un razonamiento de indagación, el niño solicita la fuente de información, evalúa la calidad de la fuente y emite con base en ello un juicio y una valoración.

A fin de indagar como una primera aproximación la percepción sobre aspectos asociados a la Naturaleza de la Ciencia, se les realizó una entrevista a 8 niños que han asistido a los clubes por más tiempo. Bajo las categorías: Como se construye la Ciencia, el papel de la imaginación y la creatividad en la interpretación de los datos y elaboración de teorías, como trabaja la comunidad científica y la utilidad de la ciencia, un concentrado de las afirmaciones se muestra a continuación.

Un niño "DM" con 12 años de edad con una participación bajo una dirección personalizada 6 años, durante los cuales ha participado activamente en actividades de ciencia. Tiene una percepción favorable hacia la ciencia, trabaja en colaborativo con "A", se distribuyen las tareas, seleccionan lo que tienen que trabajar de acuerdo a las habilidades de cada quien, comparan resultados y si es necesario buscan ayuda de asesoría. Refieren que "trabajar en equipo permite tener más ideas"

Asimismo, 4 niños, 3 hombres "J", "P" y "A", y 1 mujer con 4 años en el club de ciencias, han asistido de manera continua a los talleres; expresaron que la Ciencia ayuda a resolver problemas aunque también crea otros como "inventa envases que contaminan", describieron que para resolver un problema tienen que buscar como explicar, es decir, identifican claramente que un problema al ser analizado por diferentes disciplinas científicas se obtienen perspectivas diferentes y los experimentos varían de acuerdo a ello. Afirman que los experimentos a veces no resultan como ellos esperan

Las niñas "DF", "N" y "S" reconocen la metodología de trabajo, al responder sobre el tema dieron ejemplos específicos de propuestas a desarrollar. Proponen temas de trabajo, buscan información en libros, internet, hace algún experimento, por ejemplo, al preguntarse sobre un problema, el caso de "la saliva", buscan información, tratan de reproducir la saliva de acuerdo a la información recabada, buscan una disciplina desde donde puedan basarse para 
fundamentar su proyecto y su propuesta, identificaron las propiedades físicas de la saliva, elaboraron un material con características físicas similares y buscaron información sobre la salud y de ahí obtienen sus conclusiones.

De igual forma, 3 niños "R" " $M$ " y "O" han trabajado por espacio de 2 años, verbalizaron que cuando se integraron al club pudieron ver que se tenían que organizar y seguir un procedimiento para resolver los problemas "no solo lo que se les ocurriera" sino que tenían que decir porque trabajar de una manera y no de otra. "La ciencia sirve para resolver problemas".

En general, los niños afirman que la ciencia es útil, una desea estudiar un doctorado en "química molecular y biología", es decir, reconoce las disciplinas pero todavía no queda claro cómo se hace una delimitación a las áreas del conocimiento. "D" no sabe que estudiar "J" quiere ser bombero pero, inventará una manera para que el agua alcance los edificios altos.

A seis años de haber iniciado la metodología se ha encontrado que el interés de los niños disminuye si trabajan en proyectos largos, una recomendación es que las actividades se complementen o se combinen con otros proyectos.

Si bien es cierto algunos niños asisten por interés propio, otros son llevados por sus padres a las actividades, si después de un tiempo no se ha logrado captar la atención del niño, termina desertando.

Se requiere contar con personal de apoyo para la realización de tareas específicas, cuando el proyecto demanda carpintería, uso de alguna herramienta, software, etc.

Los padres acompañan las tareas pero no deben resolver los problemas a los niños, algunos desean que sus hijos ganen las competencias y terminan realizando parte del trabajo, lo cual es contrario al objetivo del programa, desafortunadamente la presión social y los deseos de ser los mejores causa en ocasiones que los niños se centren en obtener premios más que en el aprendizaje, algunos se desmotivan si no obtienen una acreditación o un premio.

Actualmente se trabaja en la adecuación de la metodología para ser aplicada en otros contextos educativos y sociales, con niños en edades comprendidas entre los 5 y 14 años. También, se realiza una compilación de las diferentes secuencias didácticas, con las rúbricas y materiales de evaluación para ser incluidas en un libro de innovación docente. 


\section{CONSIDERACIONES Y PERSPECTIVAS}

Esta metodología debe seguir siendo refinada con base en las experiencias y el contexto, ya que se está actualmente trabajando en niños de zonas urbanas y zonas rurales que hablan español y alguna lengua indígena, así como en niños con capacidades especiales. Se espera que los niños que se han integrado a este programa desde el 2011, continúen con su formación científica y puedan, en un futuro cercano y a un mediano plazo, realizar un estudio de caso donde se muestre su desarrollo cognitivo y habilidades científicas. También se está trabajando en la elaboración de materiales impresos basados en las experiencias con los niños para que puedan ser reproducidos por profesores de otras regiones en diferentes países. La estrategia centrada en talleres científicos impartidos por clubes de ciencia en escenarios no formales, que utiliza como base la aplicación del método científico y la presentación de proyectos en concursos de ciencias y otros escenarios de divulgación, nos ha permitido formar a aproximadamente 50 niños en zonas urbanas y zonas rurales, quienes además de aprender un contenido científico han desarrollado habilidades investigativas y de comunicación.

El acercamiento con los niños ha permitido identificar que reconocen el método científico, que la ciencia se hace en colectivo, la importancia de basar sus propuestas en conocimiento existente y explorar el problema lo suficiente como para encontrar aspectos diferentes de como estudiarlo, reconocen la importancia de hacer nuevas propuestas y de usar la imaginación para poder resolver los problemas con los materiales a su alcance. Los niños identifican la utilidad de la ciencia y aunque reconocen algunas disciplinas científicas como la física, matemáticas, química y biología, aún tienen dificultades para identificar los campos de acción de algunas otras, el trabajo con estos niños ha permitido estructurar una forma de trabajo que ha dado pie a una propuesta formal de trabajo con un grupo de niños de mayor edad a través de la Escuela de pequeños ingenieros, espacio académico que incorpora actividades artísticas como pintura, dibujo y escultura en el diseño de los proyectos. Este trabajo exploratorio nos ha dado pauta para identificar áreas de oportunidad y nos permitirá en un segundo trabajo mostrar evidencias del avance individual de los asistentes.

\section{REFERENCIAS}

ACEVEDO, J. A. Reflexiones sobre las finalidades de la enseñanza de las ciencias Educación científica para la ciudadania. Revista Eureka sobre Enseñanza y Divulgación de las Ciencias, v.1, n.1, p.3-15, ene/2004. Disponible en: 
https://rodin.uca.es/xmlui/bitstream/handle/10498/16530/Reflexiones\%20sobre\%20las\%20fin alidades $\% 20 \mathrm{de} \% 201 \mathrm{a} \% 20$ ense $\% \mathrm{C} 3 \% \mathrm{~B} 1 \mathrm{anza} \% 20 \mathrm{de} \% 201 \mathrm{as} \% 20$ ciencias.pdf. Acceso en: 10/abril/2020.

ACEVEDO, J.A.; VÁZQUEZ, A. A.; ACEVEDO, R. P.; MANASSERO, M. A. Un estudio sobre las actitudes y creencias CTS del profesorado de primaria, secundaria y universidad. Tarbiya: Revista de investigación e innovación educativa. n.30, p.5-27. Oct/2002. Disponible en: https://www.oei.es/historico/salactsi/acevedo15.htm. Acceso en: 11/nov/2019.

BIRCHER, L.; SANSENBAUGHER, B. Start a science club: create citizen scientists while teaching content and helping your community. The Science Teacher. v.82, n.8., p.139. Nov/2015. Disponible: https://www.questia.com/library/journal/1G1-433386103/start-ascience-club-create-citizen-scientists-while. Acceso en: 29/nov/2019.

CAMPANARIO, J. M.; MOYA, A. ¿Cómo enseñar ciencias? Principales tendencias y propuestas. Enseñanza de las Ciencias, v.17 n.2, p.179-192. 1999. Disponible en: https://www.raco.cat/index.php/Ensenanza/article/view/21572. Acceso en: 14/nov/2019.

COCA, J. R.; VALERO, M. J. A.; NASCIMENTO, E. M. M. Imaginarios sociales de la biotecnología: el contexto económico-empresarial. Revista de Fomento Social. v.69, n.275, p.283-311. Jul/Sep/2014. Disponible en:

https://www.revistadefomentosocial.es/rfs/article/view/1656. Acceso en: 15/nov/2019.

DUSCHL, R. A.; SCWEINGRUBER, H. A.; SHOUSE, A. W. Taking science to school: Leaning and teaching science in grades K-8. Washington, DC: National Academies Press. 2007.

ESPAÑA, FEYCYT, OEI, RICYT. Encuesta en grandes núcleos urbanos, Proyecto Estándar Iberoamericano de Indicadores de Percepción Pública, Cultura Científica y Participación Ciudadana. Cultura científica en Iberoamérica. 2009.

FERNÁNDEZ, G.; SHAW, R. Youth participation in disaster risk reduction through science clubs in the Philippines. Disasters. v.39, n.2, p.279-294. Nov/2014. Disponible en: https://onlinelibrary.wiley.com/doi/abs/10.1111/disa.12100. Acceso en: 5/enero/2020.

MÉXICO, INEGI. Encuesta sobre la Percepción Pública de la Ciencia y la Tecnología 2015 (ENPECYT). 2017. Disponible en:

http://internet.contenidos.inegi.org.mx/contenidos/Productos/prod_serv/contenidos/espanol/bv inegi/productos/nueva_estruc/702825094775.pdf .Acceso en: 20/enero/2020

EE.UU., National Science Teacher Association NSTA. Disponible en:

http://nstacommunities.org/blog/2010/06/07/starting-a-science-club/NSTA Acceso en:

6/enero/2020.

KESELMAN, A.; LEVIN, D. M.; HUNDAL, S.; KRAMER, J. F.; MATZKIN, K.; DUTCHER, G. Teaching Environmental Health Science for Informed Citizenship in the Science. Classroom and Afterschool Clubs. International Journal of Science in Society. v.3, n.3, p31-44. 2012. 
PETRINJAK, L. Competing to Learn. WebNews Digest. NSTA Reports. Disponible en: http://www.nsta.org/publications/news/story.aspx?id=56743 2009. Acceso en: 10/enero/2020.

LAPERTOSA. Sergio; BURGOS, Alejandro; FIRMAN, Andres, BURGHARDT, Mariela; ROMERO, Gilda. Una aproximación para despertar vocaciones STEM en el nivel médio en: XII CONGRESO DE TECNOLOGÍA EN EDUCACIÓN Y EDUCACIÓN EN TECNOLOGÍA, XII, 2017, Matanzas, Cuba. Memorias. Pag. 94-108.

MILLER, K.; SONNERT, G.; SADLER, P. The influence of students' participation in STEM competitions on their interest in STEM careers. International Journal of Science

Education. Part B, v.8, n.2, p.95-114, 2018. DOI: 10.1080/21548455.2017.1397298 Acceso en: $10 /$ enero/2020.

ARGENTINA, BRASIL Y MÉXICO. RICYT. EL ESTADO DE LA CIENCIA. Principales Indicadores de Ciencia y Tecnología Iberoamericanos / Interamericanos 2017. Disponible en: http://www.ricyt.org/wp-content/uploads/2017/10/files Estado-de-la-Ciencia2017 El_Estado_de_la_Ciencia_2017_Completo.pdf Acceso en: 25/nov/2019.

SAHIN, A. STEM Clubs and Science Fair Competitions: Effects on Post-Secondary Matriculation. Journal of STEM Education v.14, n.1, p.1-8. Ene/2013. Disponible en: https://www.researchgate.net/publication/255682510_STEM_Clubs and Science_Fair_Com petitions_Effects_on_Post-Secondary_Matriculation.

SAHIN, A.; AYAR, M. C.; ADIGUZEL, T. STEM Related After-School Program Activities and Associated Outcomes on Student Learning. Educational Sciences: Theory and Practice. v.14, n.1 p.309-322, 2014. Disponible en: https://eric.ed.gov/?id=EJ1038710.

SANZ, M., N.; LÓPEZ, C. J. A. Cultura científica para la educación del siglo XXI. Revista Iberoamericana de Educación. v.58, p.35-59. Ene/2012. Disponible en: https://rieoei.org/RIE/article/view/472. Acceso en: 10/enero/2020.

MÉXICO. SEP.. Programas de estudio 2011. Guía para el Maestro. Educación Básica. Secundaria. Ciencias. Dirección General de Desarrollo Curricular y de la Dirección General de Formación Continua de Maestros en Servicio de la Subsecretaría de Educación Básica de la Secretaría de Educación Pública. México, D.F. 2011.

SUÁREZ, C. P. Columna de frente a la Ciencia. Revista Universitarios Potosinos, Órgano de Divulgación científica, v.10, n.178, p.9, Ago/2014. Disponible en:

http://casaviva.uaslp.mx/universitarios potosinos/UP\%20178.pdf.

SUÁREZ, C. P.; OJEDA, G. M.; MORA, C.; MARTÍNEZ, J. R. El efecto del aprendizaje en proyectos colaborativos y contextualizados en la percepción del alumno sobre la Física y su conexión con el mundo real. Revista Académica de Investigación Tlatemoani. n.14. p.1-23. Dic/2013. ISSN: 19899300. Disponible en:

http://www.eumed.net/rev/tlatemoani/14/percepcion-alumno-fisica.pdf.

SUÁREZ, C. P.; ARRIBAS, G. E.; ESCOBAR, I.; GAMBOA, L. R.; Arroyo, D. G.; Vidales, F. S. The multidisciplinary application seminar in engineering as stage for development of higher order cognitive skills. Em: PROCEEDINGS OF INTED2016 CONFERENCE, 
Valencia, Spain. Procedings. IATED. Marzo/2016. p.2724-2732. Disponible en: https://ibrary.iated.org/view/SUAREZRODRIGUEZ2016MUL.

VIEGAS, A. The importance of Science Club's: Methods used is a School Case. Teaching Science: The Journal of the Australian Science Teachers Association. v.50, n.4, p.22-24. 2004.

\section{LOS GRADOS}

\section{AGRADECIMIENTOS}

Agradecemos a la Universidad Autónoma de San Luis Potosí, por facilitarnos las instalaciones para llevar a cabo los talleres, a la Presidencia Municipal de Tamazunchale por su colaboración en la organización de los concursos y presentaciones de los trabajos en los diferentes escenarios. A las diversas escuelas de los Municipios de Tamazunchale, San Luis Potosí y a las instituciones educativas en el Estado de San Luis Potosí que nos han abierto las puertas, a los directivos, maestros padres de familia y niños que han contribuido con su entusiasmo en las actividades, muchas veces cubriendo con los gastos de traslado para llevar a cabo las presentaciones en diversos escenarios.

\section{FINANCIAMIENTO}

Financiado por lo(s) propio(s) autor(es).

\section{CONTRIBUCIÓN DE AUTORIA}

Resumo/Abstract/Resumen: Carmen del Pilar Suárez Rodríguez, Roxana de León Lomelí, Rubi Gamboa-León y Cynthia Zamora Pedraza

Introducción: Carmen del Pilar Suárez Rodríguez, Roxana de León Lomelí, Rubi Gamboa-León y Cynthia Zamora Pedraza

Marco teórico: Carmen del Pilar Suárez Rodríguez, Roxana de León Lomelí, Rubi Gamboa-León y Cynthia Zamora Pedraza

Análisis de datos: Carmen del Pilar Suárez Rodríguez, Roxana de León Lomelí, Rubi Gamboa-León y Cynthia Zamora Pedraza

Discusión de los resultados: Carmen del Pilar Suárez Rodríguez, Roxana de León Lomelí, Rubi Gamboa-León y Cynthia Zamora Pedraza

Conclusión y consideraciones finales: Carmen del Pilar Suárez Rodríguez, Roxana de León Lomelí, Rubi GamboaLeón y Cynthia Zamora Pedraza

Referencias: Carmen del Pilar Suárez Rodríguez, Roxana de León Lomelí, Rubi Gamboa-León y Cynthia Zamora Pedraza

Revisión del manuscrito: Carmen del Pilar Suárez Rodríguez, Roxana de León Lomelí, Rubi Gamboa-León y Cynthia Zamora Pedraza

Aprobación de la versión final publicada: Carmen del Pilar Suárez Rodríguez, Roxana de León Lomelí, Rubi Gamboa-León y Cynthia Zamora Pedraza

\section{CONFLICTO DE INTERESES}

Los autores declaran no tener ningún conflicto de intereses de orden personal, comercial, académico, político y financiero referente al manuscrito.

\section{DISPONIBILIDAD DE DATOS DE LA INVESTIGACIÓN}

El conjunto de datos que da soporte a los resultados de la investigación fue publicado en el propio artículo.

\section{CONSENTIMIENTO DE USO DE IMÁGENES}

Son imágenes de autoría propia y contamos con la autorización de los padres de familia de los niños y de quienes ahí aparecen. 


\section{CÓMO CITAR - ABNT}

RODRÍGUEZ, Carmen del Pilar Suárez; LEÓN-LOMELÍ, Roxana de; GAMBOA-LEÓN, Rubi; ZAMORAPEDRAZA, Cynthia. Formación Científica STEM, Experiencias de Aprendizaje a partir de Clubes de Ciencias.

REAMEC - Rede Amazônica de Educação em Ciências e Matemática. Cuiabá, v. 9, n. 1, e21016, janeiroabril, 2021. DOI: 10.26571/reamec.v9i1.11192.

\section{CÓMO CITAR - APA}

RODRÍGUEZ, C. P. S.; LEÓN-LOMELÍ, R.; GAMBOA-LEÓN, R. \& ZAMORA-PEDRAZA, C. (2021). Formación Científica STEM, Experiencias de Aprendizaje a partir de Clubes de Ciencias. REAMEC - Rede Amazônica de Educação em Ciências e Matemática, 9 (1), e21016 DOI: 10.26571/reamec.v9i1.11192.

\section{LICENCIA DE USO}

Con licencia de Creative Commons Attribution-NonCommercial 4.0 International License (CC BY-NC 4.0). Esta licencia le permite compartir, copiar, redistribuir el manuscrito en cualquier medio o formato. Además, permite adaptar, remezclar, transformar y construir sobre el material, siempre que se dé el debido crédito por la autoría y publicación inicial en esta revista.

\section{DERECHOS DE AUTOR}

Los derechos de autor son mantenidos por los autores, quienes otorgan a REAMEC - Red Amazónica para la Educación Científica y Matemática - los derechos exclusivos de primera publicación. Los autores no serán remunerados por la publicación de trabajos en esta revista. Los autores están autorizados a asumir contratos adicionales por separado, para la distribución no exclusiva de la versión del trabajo publicado en esta revista (ej .: publicación en un repositorio institucional, en un sitio web personal, publicación de una traducción, o como capítulo de un libro), con reconocimiento de autoría y publicación inicial en esta revista. Los editores de la Revista tienen derecho a realizar ajustes textuales y adaptarlos a las reglas de la publicación.

\section{PUBLISHER}

Universidad Federal de Mato Grosso. Programa de Posgrado en Educación en Ciencias y Matemáticas (PPGECEM) de la Red Amazónica de Educación en Ciencias y Matemáticas (REAMEC). Publicación en el portal de revistas de la UFMT. Las ideas expresadas en este artículo son responsabilidad de sus autores y no necesariamente representan la opinión de los editores o de la universidad.

\section{EDITOR}

Marcel Thiago Damasceno Ribeiro

\section{HISTÓRICO}

Enviado: 29 de septiembre de 2020.

Aprobado: 14 de octubre de 2020.

Publicado: 28 de enero de 2021. 


\section{Anexo 1.}

Publicación en extenso y poster del proyecto "Aprender de insectos es divertido".
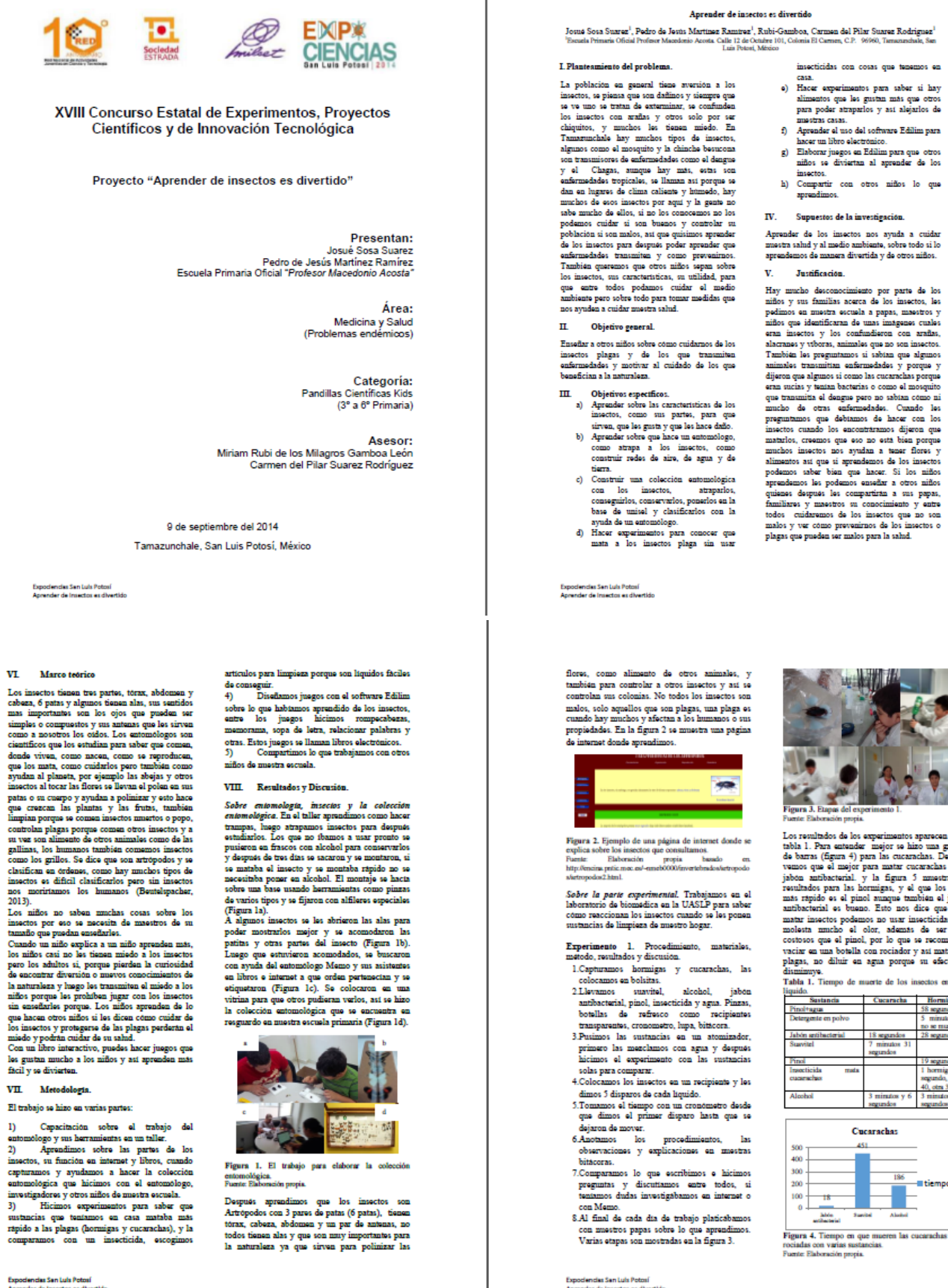

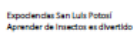

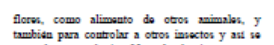

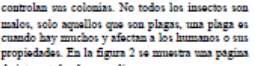
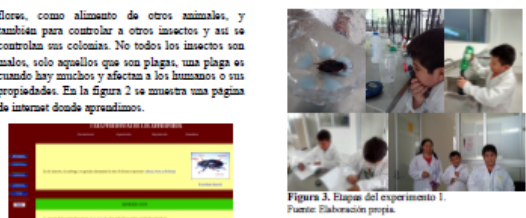

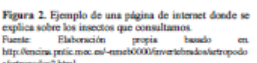

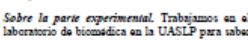

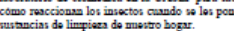

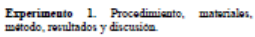

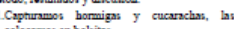

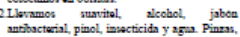

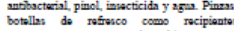

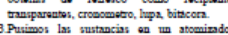

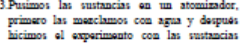

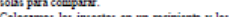

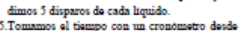

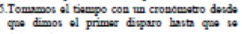

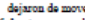

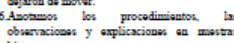

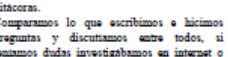

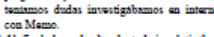

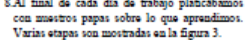
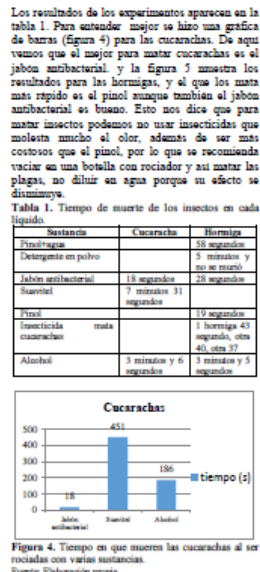

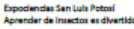

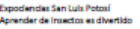



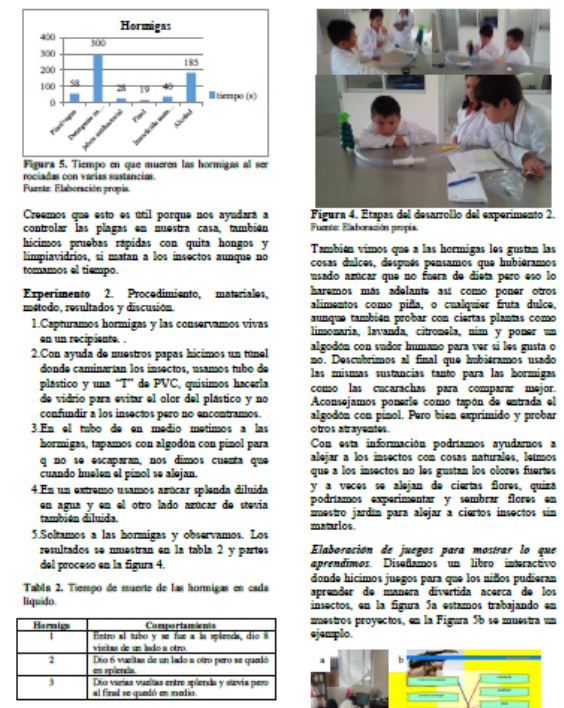

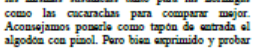

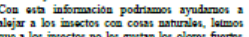

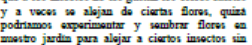

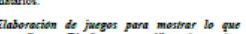

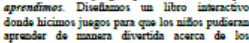

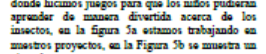
di

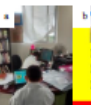

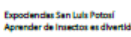

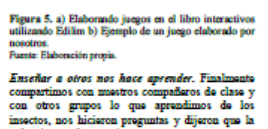

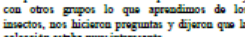

Ix. Conderiones

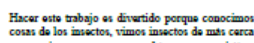

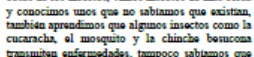

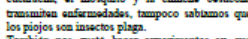

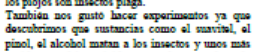

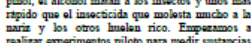

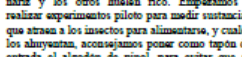

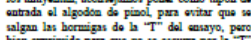

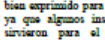

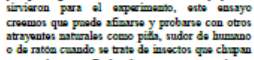

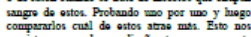

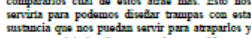

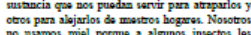

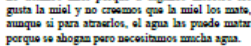

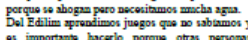

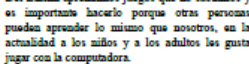

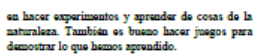

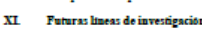

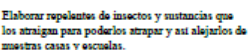

XII Referescias

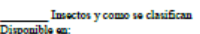

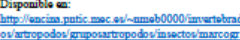

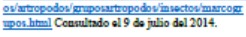

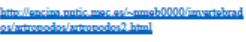

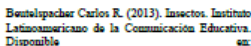

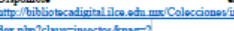
(1)

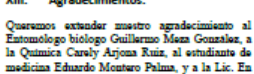

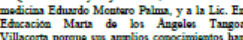

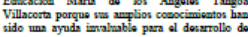

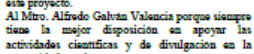

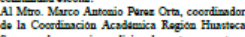

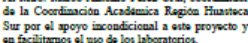

Descripionan del grado de inoovacion.

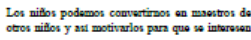

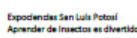
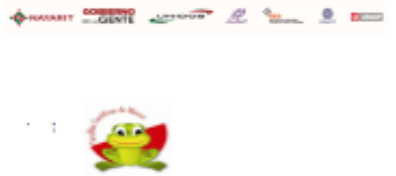

EXPOCIENCIENCIAS NACIONAL 2014 Tepic, Nayarit

Aprender de insectos es divertido MS-SLP. 14030

Josue Soca Susez
Pedro de Jecía Martinez Ramic

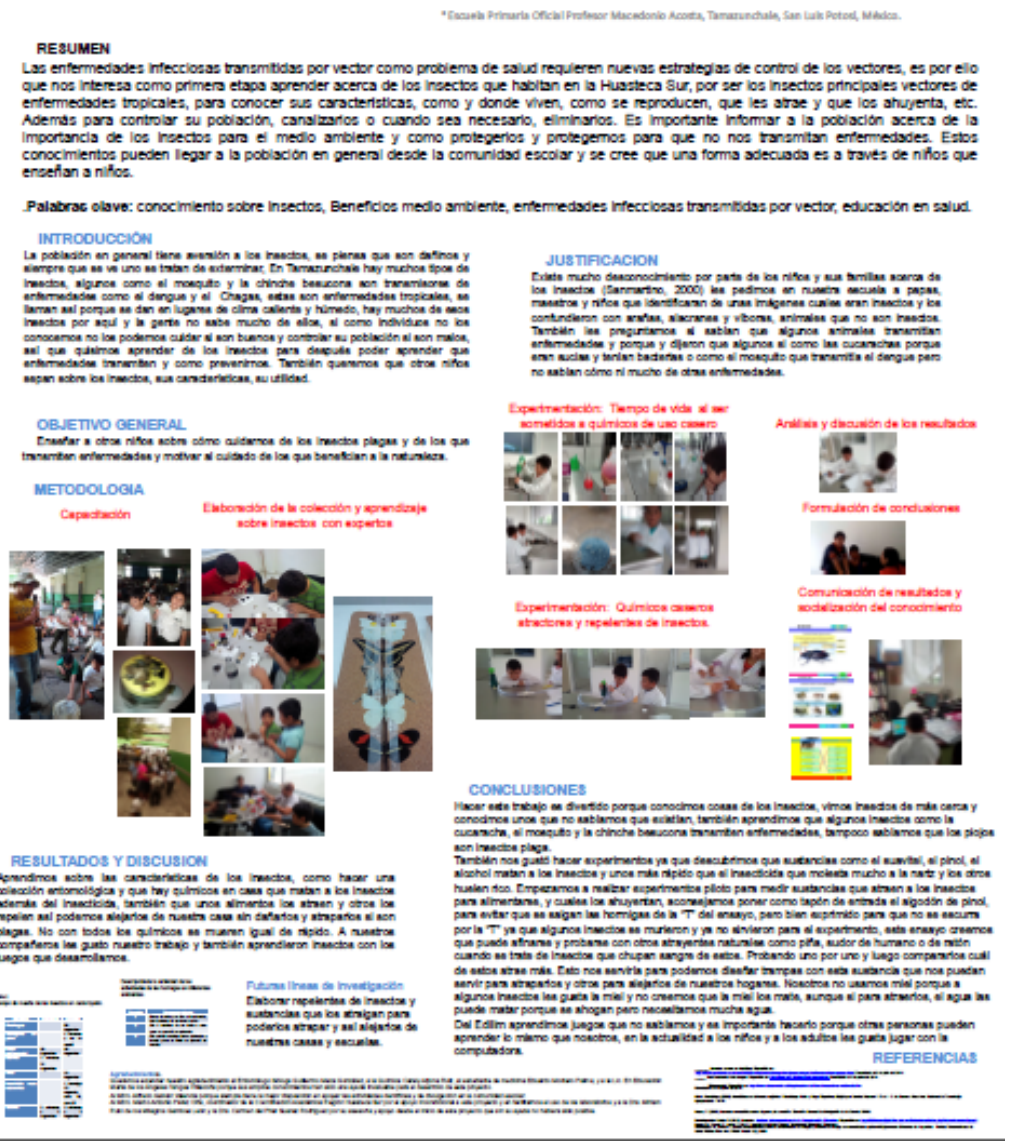

